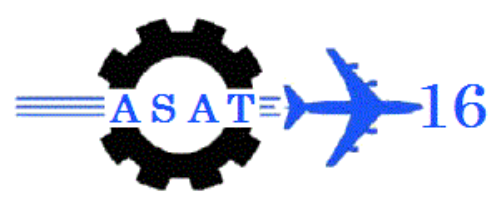

\title{
A Systematic Approach for the Study and Analysis of Vehicle Dynamics Using Design of Experiments
}

\author{
M. Mohsen ${ }^{*}$, H. M. Eltaher ${ }^{\dagger}$, A. M. Sharaf ${ }^{*}$ and S. M. El-demerdash ${ }^{\S}$
}

\begin{abstract}
Suspension system design plays an important role in improving passenger comfort and road holding capabilities of the vehicle. The primary function of the vehicle suspension system is to isolate the vehicle body from road surface irregularities as well as to control the body and wheel motions. This study presents the use of analysis of variance (ANOVA) in studying the effects of vehicle design parameters, such as the spring stiffness and the shock absorber damping coefficient on the discomfort parameters which are the vehicle body vertical acceleration (Bac), suspension working space (SWS) and the dynamic tire load (DTL). The model presented in this study is a half vehicle model built in MATLAB/SIMULINK environment, and it is validated with a published work and the comparison shows very good agreement between the two models. Different values of design parameters are used as an input to the vehicle model, and the output data are analyzed using MINITAB 17 software program to plot the main and interaction effect between all design parameters and discomfort parameters. The results show that variation of both suspension stiffness \& damping coefficient significantly affects the vehicle suspension working space, and have small effect on the front and rear dynamic tire loads. While, as the front suspension stiffness \& damping coefficient increases the vehicle body vertical acceleration decreases for these two types of roads.
\end{abstract}

Keywords: Vehicle dynamics, Passive suspension system, Half vehicle model, Ride comfort, Design of experiments, and OFAT.

\section{Nomenclatures}

ANOVA Analysis of variance

Bac Body vertical acceleration

DOE Design of experiments

DOF Degree of freedom

DTLf Front dynamic tire load

DTLr Rear dynamic tire load

OFAT One factor at a time

SWSf Front suspension working space

SWSr Rear suspension working space

\footnotetext{
* PhD Student, Automotive Engineering Dept., Military Technical College

${ }^{\dagger}$ Lecturer, Automotive Engineering Dept., Military Technical College

¥ Associate Professor, Head of Automotive Engineering Dept., Military Technical College

${ }^{\S}$ Professor, Helwan University, Faculty of Engineering and Technology, Mataria, Cairo, Egypt
} 


\section{Introduction}

The vehicle suspension system is responsible for drive comfort and safety as the suspension carries the vehicle-body and transmits all forces between body and road [1]. The Suspension system is an assembly of springs, shock absorbers and linkages that connects a vehicle to its wheels [2]. The primary functions of a vehicle suspension system are to:

(a) Provide vertical compliance so the wheels can follow the uneven road hence isolating the chassis from road roughness.

(b) Maintain the wheels in the proper steer and camber attitudes to the road surface.

(c) React to the resulting forces from tires.

(d) Keep the tires in contact with the road with minimal load variations [3].

The commercial vehicles today use passive suspension system to control the dynamics of a vehicle's vertical motion as well as pitch and roll motions. The performance of a suspension system for stochastic response is commonly assessed using three discomfort parameters: ride comfort, suspension working space, and dynamic tire load [4].

The objective of this paper is to investigate the effect of design parameters (suspension stiffness \& damping coefficient) on vehicle discomfort parameters. This is accomplished using Analysis of Variance (ANOVA) statistical techniques. This is an innovative approach compared to the traditional parametric study which looks at the effect of changing one factor at a time (OFAT).

Engineers and scientists often perform OFAT experiments, which vary only one factor or variable at a time while keeping other factors fixed. But if we want to vary several factors simultaneously, ANOVA will be a more efficient method [5]. The reasons stated for favoring the use of ANOVA over OFAT are:

(a) ANOVA maximizes the information gain using the minimum number of experiments, thus minimizing time and cost.

(b) OFAT cannot estimate interaction effects between input parameters on output responses.

Few publications are found related to the subject matter of this paper. The effects of spring stiffness and shock absorber damping coefficient on the vertical acceleration of the driver's body, suspension deformation and dynamic tire load were studied by Dragan Sekulić and Vlastimir Dedović [6]. The results of the analysis show that the parameters which ensured good oscillatory comfort of the driver were conflicting with the parameters which ensured the greatest stability of the bus suspension and the corresponding wheel travel. In terms of the driver's oscillatory comfort, the bus suspension system should have a spring with a low stiffness and a shock absorber with a low damping coefficient. On the other hand for better handling and stability both spring rate and damping coefficient should have higher values, however this will worsen ride comfort. Bor-Tsuen Wang [7] also studied the effect of suspension parameters on the ride quality of a full tractor and trailer using ANOVA and the results show that the suspension damping coefficient significantly influences the suspension travel distance; i.e. the higher the damping the lower the suspension travel. V. R. Naik $\dot{A}$ and S. H. Sawant $\dot{A}[8]$ studied the effect of varying the vehicle suspension parameters (spring stiffness and shock absorber damping coefficient) on the seat displacement and settling time using the Taguchi design of experimental method. The optimum suspension parameters are predicted using Taguchi analysis to minimize displacement and settling time of seat for the quarter car model. The results show that the settling time of the seat mass was reduced from 2 sec to $1.7 \mathrm{sec}$ using optimum suspension parameters. 


\section{Method}

In this work ANOVA was used to study the effect of the input design parameters on the output response (vehicle discomfort parameters i.e., body acceleration, suspension working space and dynamic tire load). ANOVA assesses the importance of one or more factors by comparing the response variable means at different factor levels. For demonstration, a four degree of freedom vehicle model is developed using MATLAB software program and validated with published work.

Full factorial is a type of design of experiments used in this study to calculate all possible combinations between vehicle design parameters and its effect on the discomfort parameters. This design includes all combinations of input parameters. It is used in this work because the number of input parameters is limited (4-input parameters). However, other types of design of experiments are used when the number of input parameters is large, which increases the cost of running experiments [9].

Finally, the results are analyzed using MINITAB software package which is used specially for this type of data analysis. Fig. 1. shows a schematic drawing of the general steps involved in the DOE Method.

\section{Model Description}

This model is represented by two wheel masses $\left(\mathrm{m}_{\mathrm{f}}, \mathrm{m}_{\mathrm{r}}\right)$ for front and rear wheels and one body mass $\left(\mathrm{m}_{\mathrm{b}}\right)$ for vehicle body. The vehicle body and wheels are connected with linear springs and viscous dampers for passive suspension. These elements are described by front and rear stiffness coefficients $\left(\mathrm{K}_{\mathrm{f}}, \mathrm{K}_{\mathrm{r}}\right)$ and front and rear damping coefficients $\left(\mathrm{C}_{\mathrm{f}}, \mathrm{C}_{\mathrm{r}}\right)$. Tires are represented by springs with stiffness's $\left(\mathrm{K}_{\mathrm{tf}}, \mathrm{K}_{\mathrm{tr}}\right)$.

The vehicle model has four degrees of freedom which are vertical displacements of body and wheel masses $\left(\mathrm{m}_{\mathrm{b}}, \mathrm{m}_{\mathrm{f}}\right.$ and $\mathrm{m}_{\mathrm{r}}$, ) and body pitch rotation about vehicle center of gravity $\left(\Theta_{\mathrm{b}}\right)$ as shown in Fig. 2.

The equation of motion can be derived using Newton's 2nd law of motion as follows:

$$
\begin{aligned}
& \mathrm{m}_{\mathrm{f}} \ddot{Z}_{\mathrm{f}}=\mathrm{K}_{\mathrm{f}}\left(\mathrm{Z}_{\mathrm{b}}-\mathrm{Z}_{\mathrm{f}}+\mathrm{a} \theta_{\mathrm{b}}\right)+\mathrm{C}_{\mathrm{f}}\left(\dot{Z}_{\mathrm{b}}-\dot{Z}_{\mathrm{f}}+\mathrm{a} \dot{\theta}_{\mathrm{b}}\right)-\mathrm{K}_{\mathrm{tf}}\left(\mathrm{Z}_{\mathrm{f}}-\mathrm{Z}_{\mathrm{rf}}\right) \\
& \mathrm{m}_{\mathrm{r}} \ddot{Z}_{\mathrm{r}}=\mathrm{K}_{\mathrm{r}}\left(\mathrm{Z}_{\mathrm{b}}-\mathrm{Z}_{\mathrm{r}}-\mathrm{b} \theta_{\mathrm{b}}\right)+\mathrm{C}_{\mathrm{r}}\left(\dot{Z}_{\mathrm{b}}-\dot{Z}_{\mathrm{r}}-\mathrm{b} \dot{\theta}_{\mathrm{b}}\right)-\mathrm{K}_{\mathrm{tr}}\left(\mathrm{Z}_{\mathrm{r}}-\mathrm{Z}_{\mathrm{rr}}\right) \\
& \mathrm{m}_{\mathrm{b}} \ddot{Z}_{\mathrm{b}}=-\mathrm{K}_{\mathrm{f}}\left(\mathrm{Z}_{\mathrm{b}}-\mathrm{Z}_{\mathrm{f}}+\mathrm{a} \theta_{\mathrm{b}}\right)-\mathrm{C}_{\mathrm{f}}\left(\dot{\mathrm{Z}}_{\mathrm{b}}-\dot{\mathrm{Z}}_{\mathrm{f}}+\mathrm{a} \dot{\theta}_{\mathrm{b}}\right)-\mathrm{K}_{\mathrm{r}}\left(\mathrm{Z}_{\mathrm{b}}-\mathrm{Z}_{\mathrm{r}}-\mathrm{b} \theta_{\mathrm{b}}\right)-\mathrm{C}_{\mathrm{r}}\left(\dot{\mathrm{Z}}_{\mathrm{b}}-\dot{\mathrm{Z}}_{\mathrm{r}}-\mathrm{b} \dot{\theta}_{\mathrm{b}}\right) \\
& \mathrm{I}_{\mathrm{b}} \ddot{\theta}_{\mathrm{b}}=-\mathrm{a}\left[\mathrm{K}_{\mathrm{f}}\left(\mathrm{Z}_{\mathrm{b}}-\mathrm{Z}_{\mathrm{f}}+\mathrm{a} \theta_{\mathrm{b}}\right)+\mathrm{C}_{\mathrm{f}}\left(\dot{\mathrm{Z}}_{\mathrm{b}}-\dot{\mathrm{Z}}_{\mathrm{f}}+\mathrm{a} \dot{\theta}_{\mathrm{b}}\right)\right]+\mathrm{b}\left[\mathrm{K}_{\mathrm{r}}\left(\mathrm{Z}_{\mathrm{b}}-\mathrm{Z}_{\mathrm{r}}-\mathrm{b} \theta_{\mathrm{b}}\right)+\mathrm{C}_{\mathrm{r}}\left(\dot{\mathrm{Z}}_{\mathrm{b}}-\dot{\mathrm{Z}}_{\mathrm{r}}-\mathrm{b} \dot{\theta}_{\mathrm{b}}\right)^{(4}\right)
\end{aligned}
$$

Where:

$\mathrm{Z}_{\mathrm{rf}}, \mathrm{Z}_{\mathrm{rr}} \quad$ Front and rear road input excitations

$\dot{\mathrm{Z}}, \ddot{\mathrm{Z}} \quad$ Vertical velocity and vertical acceleration

$\dot{\theta}, \ddot{\theta} \quad$ Angular velocity and Angular acceleration 
b Distance from rear suspension to center of vehicle

$\mathrm{I}_{\mathrm{b}} \quad$ Pitch moment of inertia

The model states are assigned as:

$\mathrm{X}_{1}=\mathrm{Z}_{\mathrm{f}} \quad$ Front un-sprung mass bounce displacement

$\mathrm{X}_{2}=\mathrm{Z}_{\mathrm{r}} \quad$ Rear un-sprung mass bounce displacement

$\mathrm{X}_{3}=\mathrm{Z}_{\mathrm{b}} \quad$ Sprung mass bounce displacement

$\mathrm{X}_{4}=\theta_{\mathrm{b}} \quad$ Sprung mass pitch angle

$\mathrm{X}_{5}=\dot{\mathrm{Z}}_{\mathrm{f}} \quad$ Front un-sprung mass bounce rate

$\mathrm{X}_{6}=\dot{\mathrm{Z}}_{\mathrm{r}} \quad$ Rear un-sprung mass bounce rate

$\mathrm{X}_{7}=\dot{\mathrm{Z}}_{\mathrm{b}} \quad$ Sprung mass bounce rate

$\mathrm{X}_{8}=\dot{\theta}_{\mathrm{b}} \quad$ Sprung mass pitch angular velocity

The state vector is:

$[\mathbf{x}]=\left[\begin{array}{llllllll}\mathbf{x}_{1} & \mathbf{x}_{2} & \mathbf{x}_{3} & \mathbf{x}_{4} & \mathbf{x}_{5} & \mathbf{x}_{6} & \mathbf{x}_{7} & \mathbf{x}_{8}\end{array}\right]^{\mathrm{T}}$

The state space can be represented in equation (7):

$$
\begin{aligned}
& \dot{\mathrm{X}}=\mathrm{AX}+\mathrm{BU} \\
& \mathrm{Y}=\mathrm{CX}+\mathrm{DU}
\end{aligned}
$$

The matrices are given as: 


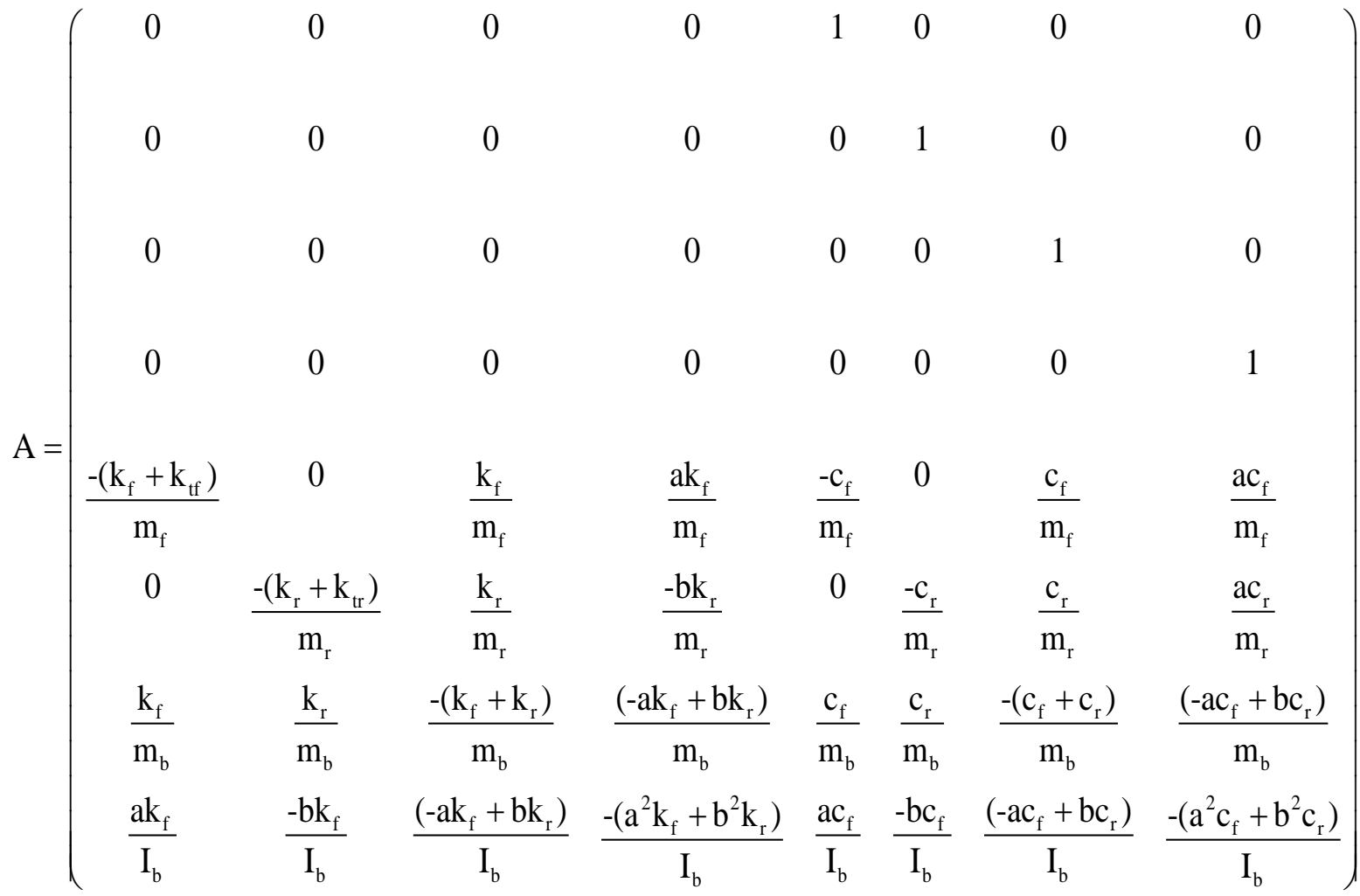

$$
\begin{aligned}
& \mathrm{B}=\left(\begin{array}{cccccccc}
0 & 0 & 0 & 0 & \frac{\mathrm{k}_{\mathrm{tf}}}{\mathrm{m}_{\mathrm{f}}} & 0 & 0 & 0 \\
0 & 0 & 0 & 0 & 0 & \frac{\mathrm{k}_{\mathrm{tr}}}{\mathrm{m}_{\mathrm{r}}} & 0 & 0
\end{array}\right)^{\mathrm{T}} \quad \mathrm{D}=\left(\begin{array}{cc}
0 & 0 \\
0 & 0 \\
0 & 0 \\
\mathrm{k}_{\mathrm{tf}} & 0 \\
0 & \mathrm{k}_{\mathrm{tr}}
\end{array}\right) \\
& \mathrm{C}=\left(\begin{array}{cccccccc}
0 & 0 & 0 & 0 & 0 & 0 & 1 & 0 \\
-1 & 0 & 1 & \mathrm{a} & 0 & 0 & 0 & 0 \\
0 & -1 & 1 & -\mathrm{b} & 0 & 0 & 0 & 0 \\
-\mathrm{k}_{\mathrm{tf}} & 0 & 0 & 0 & 0 & 0 & 0 & 0 \\
0 & -\mathrm{k}_{\mathrm{tr}} & 0 & 0 & 0 & 0 & 0 & 0
\end{array}\right)
\end{aligned}
$$

The vehicle parameters which are used for this paper are given in Table (1), see Appendix-B.

\section{Road Surface Excitation}

Two types of excitation signals representing the road surface are used in this study; the first road excitation signal is used to validate the model results. It is modeled as a step input with height $0.1(\mathrm{~m})$ as shown in Fig. 3. The vehicle model is considered travelling at a constant speed of $60 \mathrm{Km} / \mathrm{hr}$. 
The second road excitation signal [10], shown in Fig. 4, is modeled as a road bump and is used in the ANOVA analysis. This excitation signal is selected to resemble a familiar or real road profile, and is described as follows:

$$
X_{r}=\left\{\begin{array}{lcc}
a\left\{1-\cos \left(\omega_{r}(t-0.5)\right)\right\} & \text { for } & 0.5 \leq t \leq 0.5+\frac{d}{V} \\
0 & \text { otherwise }
\end{array}\right.
$$

Where:

a... is the half of the bump amplitude, $\omega_{\mathrm{r}}=2 \pi \mathrm{V} / \mathrm{d}, \mathrm{d} \ldots$ is the width of the bump and $\mathrm{V} \ldots$ is the vehicle velocity. In this study $\mathrm{a}=0.035 \mathrm{~m}, \mathrm{~d}=0.8 \mathrm{~m}, \mathrm{~V}=0.856 \mathrm{~m} / \mathrm{s}$.

\subsection{Validation of the Simulation Program}

Simulation was done using MATLAB/SIMUINK software and the results were compared with a published paper to verify the developed vehicle model. Validation of the simulation program was done by applying the same vehicle parameters and conditions used by Vladimír Gogaa to the aforementioned vehicle model [11]. The comparison in Fig.5 clearly shows that there is complete agreement between the two signals.

\section{Analysis of Variance (ANOVA)}

Analysis of variance is a standard statistical technique used to analyze experimental results [12]. It is extensively used to detect differences in average performance of groups of items under investigation. It breaks down the variation in the experimental result into separate accountable sources afterward; the parameters resulting in large variation are the identified as the ones with significant effect. This enables the use of ANOVA in studying the relative influences and significance of multiple parameters. MINITAB, which is well-known statistical software, is used in this work to compute the ANOVA parameters. In order to find out statistical significance of various factors like springs stiffness's $\left(K_{f}, K_{r}\right)$ and shock absorber damping coefficients $\left(\mathrm{C}_{\mathrm{f}}, \mathrm{C}_{\mathrm{r}}\right)$ and their interactions effect on the vehicle (Bac, SWS and DTL). Table 2 in Appendix-B shows all suspension parameters combinations and the values of the output responses.

\subsection{Main Effect Plot}

The main effects plot is used to visualize the differences between level means for one or more factors. There is a main effect when different levels of a factor affect the response differently. A main effects plot graphs the response mean for each factor level connected by a line. The effect of design parameters (or factors) can be mathematically calculated using the following simple equation:

$$
\mathrm{E}_{\mathrm{f}}=\overline{\mathrm{F}}_{(+1)}-\overline{\mathrm{F}}_{(-1)}
$$

Where: $\overline{\mathrm{F}}_{(+1)}$ is the average response at the high level setting of a factor, and $\overline{\mathrm{F}}_{(-1)}$ is the average response at the low level setting of a factor. Table 3 in Appendix-B presents the factors main effect on the output responses. 


\subsection{Interaction Effect Plot}

When the effect of one factor depends on the level of the other factor, an interaction plot is used to visualize possible interactions.

Parallel lines in an interaction plot indicate no interaction. The greater the difference in the slope between the lines the higher the degree of interaction is. Table 4 in Appendix-B shows factors interaction effects on the output response.

As it is a full factorial experiment it is possible to study all the interactions among the factors $\left(\mathrm{K}_{\mathrm{f}}, \mathrm{K}_{\mathrm{r}}, \mathrm{C}_{\mathrm{f}}, \mathrm{C}_{\mathrm{r}}\right.$ ). The interaction between two parameters (for example: $\mathrm{K}_{\mathrm{f}}$ and $\mathrm{C}_{\mathrm{f}}$ ) can be computed using the following equation:

$$
\mathrm{I}_{\mathrm{k}_{\mathrm{f}}, \mathrm{C}_{\mathrm{f}}}=\frac{1}{2}\left(\mathrm{E}_{\mathrm{k}_{\mathrm{f}}, \mathrm{C}_{\mathrm{f}}(+1)}-\mathrm{E}_{\mathrm{k}_{\mathrm{f}}, \mathrm{C}_{\mathrm{f}}(-1)}\right)
$$

Where: $E_{k_{f}, C_{f}(+1)}$ is the effect of factor $\left(K_{f}\right)$ at high level of factor $\left(C_{f}\right)$, and $E_{k_{f}, C_{f}(-1)}$ is the effect of factor $\left(\mathrm{K}_{\mathrm{f}}\right)$ at low level of factor $\left(\mathrm{C}_{\mathrm{f}}\right)$.

\section{Results and Discussion}

This section presents the results from running full factorial design simulations. The output data of the simulation are used to deduce the main and interaction effects of input design parameters on output responses. In each plot, main and interaction effects are represented by lines where the abscissa represents the limits of the design variable and the ordinate represents the limits of the output response. Considering the main effect, the slope of each line is used to determine the degree of effect of its relative input design parameter on the output response. The direction of the slope of the line indicates whether the input design parameter has positive or negative effect on considered output response. Considering the interaction effect, a plot is presented for each output response with subplots representing the interaction between every pair of input design parameters. The lines are marked to indicate the level at which the simulation was conducted, where a circle and a square represent the minimum and maximum levels respectively. The relative slope between each line pairs indicates the level of interaction between their respective input design parameters. For example, two parallel lines indicate a zero (no) interaction between the two input design parameters, on the other hand two intersecting lines indicate that there is a strong interaction.

It is clear from Fig. 6 , that both $\left(\mathrm{K}_{\mathrm{f}}\right)$ and $\left(\mathrm{C}_{\mathrm{f}}\right)$ have a significant negative effect on $(\mathrm{Bac})$ where $\left(\mathrm{K}_{\mathrm{r}}\right)$ and $\left(\mathrm{C}_{\mathrm{r}}\right)$ have small positive and negative effects respectively. However, $(\mathrm{Kf})$ has a stronger negative effect than $\left(\mathrm{C}_{\mathrm{f}}\right)$ on $(\mathrm{Bac})$, since its corresponding line has a steeper slope than $\left(\mathrm{C}_{\mathrm{f}}\right)$. This means that $(\mathrm{Bac})$ can be reduced by increasing the value of $\left(\mathrm{K}_{\mathrm{f}}\right)$. Fig. 7 , shows that both $\left(\mathrm{K}_{\mathrm{f}}\right)$ and $\left(\mathrm{C}_{\mathrm{r}}\right)$ have significant positive and negative effects on (SWSf) respectively, where $\left(\mathrm{K}_{\mathrm{r}}\right)$ and $\left(\mathrm{C}_{\mathrm{f}}\right)$ have a negative effect on (SWSf). However, $(\mathrm{Cr})$ has a stronger negative effect on (SWSf) than $\left(\mathrm{K}_{\mathrm{f}}\right)$. This means that (SWSf) can be reduced by increasing the value of $\left(\mathrm{C}_{\mathrm{r}}\right)$. Fig. 8, shows that both $\left(\mathrm{K}_{\mathrm{f}}\right)$ and $\left(\mathrm{C}_{\mathrm{r}}\right)$ have significant positive and negative effects on (SWSr) respectively, where $\left(\mathrm{K}_{\mathrm{r}}\right)$ and $\left(\mathrm{C}_{\mathrm{f}}\right)$ have a negative effect on $(\mathrm{SWSr})$. But $(\mathrm{Cr})$ has a stronger negative effect than $\left(\mathrm{K}_{\mathrm{f}}\right)$ on ( $\left.\mathrm{SWSr}\right)$. This means that (SWSr) can be reduced by increasing the value of $\left(\mathrm{C}_{\mathrm{r}}\right)$. Fig. 9 , shows that both $\left(\mathrm{K}_{\mathrm{f}}\right)$ and $\left(\mathrm{C}_{\mathrm{f}}\right)$ have significant positive and negative effects on (DTLf) respectively, where $\left(\mathrm{K}_{\mathrm{r}}\right)$ and $\left(\mathrm{C}_{\mathrm{r}}\right)$ have a very small negative and positive effect on (DTLf). However, $\left(\mathrm{K}_{\mathrm{f}}\right)$ has a stronger positive effect than $\left(\mathrm{C}_{\mathrm{f}}\right)$ on (DTLf). This means that (DTLf) can be reduced by decreasing the value of $\left(\mathrm{K}_{\mathrm{f}}\right)$. It is clear from Fig. 10, that both $\left(\mathrm{K}_{\mathrm{r}}\right)$ and $\left(\mathrm{C}_{\mathrm{r}}\right)$ have significant positive and negative effects on (DTLr) respectively, where $\left(\mathrm{K}_{\mathrm{f}}\right)$ and $\left(\mathrm{C}_{\mathrm{f}}\right)$ have small positive and negative effects on (DTLr). 
However, $\left(\mathrm{K}_{\mathrm{r}}\right)$ has a stronger positive effect on (DTLf). This means that (DTLr) can be reduced by decreasing the value of $\left(\mathrm{K}_{\mathrm{r}}\right)$. This can be explained by increasing the stiffness of the suspension results in lower suspension deflection which in turn limits the suspension working space and ultimately increasing the dynamic tire load.

Interaction plots are useful at finding the relative interaction between two design parameters on an output response. Main effects and interactions are independent of one another. You can have main effects without interactions, interactions without main effects, both, or neither. Although there is a main effect between both design parameters $\left(\mathrm{K}_{\mathrm{f}}\right)$ and $\left(\mathrm{C}_{\mathrm{f}}\right)$ there is no interaction effect between both of them. Looking at the interaction plots in Fig. 11, it is clear that there is no interaction between design parameters pairs: $\left(\mathrm{K}_{\mathrm{f}}\right.$ and $\left.\mathrm{K}_{\mathrm{r}}\right),\left(\mathrm{K}_{\mathrm{f}}\right.$ and $\left.\mathrm{C}_{\mathrm{f}}\right),\left(\mathrm{K}_{\mathrm{f}}\right.$ and $\mathrm{C}_{\mathrm{r}}$ ) on the output response (Bac) because they have parallel lines. Fig. 12, shows that the lines in the interaction plot do not intersect each other, which indicates there is no interaction between design parameters pairs: $\left(\mathrm{K}_{\mathrm{f}}\right.$ and $\left.\mathrm{K}_{\mathrm{r}}\right),\left(\mathrm{K}_{\mathrm{f}}\right.$ and $\left.\mathrm{C}_{\mathrm{f}}\right),\left(\mathrm{K}_{\mathrm{f}}\right.$ and $\left.\mathrm{C}_{\mathrm{r}}\right)$ on the output response (SWSf). It is clear from

Fig. 13, that there is no interaction effect between design parameters pairs: $\left(\mathrm{K}_{\mathrm{f}}\right.$ and $\left.\mathrm{K}_{\mathrm{r}}\right),\left(\mathrm{K}_{\mathrm{f}}\right.$ and $\left.\mathrm{C}_{\mathrm{r}}\right)$ on the output response ( $\mathrm{SWSr}$ ) because they have parallel lines. Fig. 14, shows that the lines in the interaction plot do not intersect each other, which indicates there is no interaction between design parameters on the output response (DTLf). It is clear from Fig. 15, that there is an interaction effect between design parameters pairs: $\left(\mathrm{K}_{\mathrm{r}}\right.$ and $\mathrm{C}_{\mathrm{r}}$ ) because they don't have parallel lines. However, there is no interaction effect between design parameters pairs: $\left(\mathrm{K}_{\mathrm{f}}\right.$ and $\left.\mathrm{K}_{\mathrm{r}}\right),\left(\mathrm{K}_{\mathrm{f}}\right.$ and $\left.\mathrm{C}_{\mathrm{r}}\right)$ on the output response (DTLr) because they have parallel lines.

\section{Conclusion}

In the present work, the effect of variation of suspension design parameters (spring stiffness \& shock absorber damping coefficient) on the vehicle discomfort parameters (vehicle body vertical acceleration, suspension working space and the dynamic tire load) has been studied using analysis of variance ANOVA. The vehicle discomfort parameters have been evaluated based on the variation of springs stiffness's and shock absorbers damping coefficients of the suspension system in the MATLAB software program.

The results show that variation of suspension design parameters significantly affects the vehicle discomfort parameters. Increasing of the front spring stiffness and front shock absorber damping coefficient reduces the vehicle body vertical acceleration, while increasing of the front and rear shock absorbers damping coefficients reduces the front and rear suspension working spaces for this road. The front and rear dynamic tire loads can be reduced by decreasing the stiffness's of the front and rear suspension springs respectively. Also the results indicated that increasing the stiffness of the suspension results in lower suspension deflection which in turn limits the suspension working space and ultimately increasing the dynamic tire load.

Finally, it is clear from all interaction effect plots that there is no interaction between all suspension design parameters on the vehicle discomfort parameters (output responses) because they all have parallel lines. 


\section{References}

[1] R.Kalidas. "Mathematical Modeling And Optimization Of Vehicle Passive Suspension System Using Full Car Model” ISSN: 2278 - 0211, February, 2013.

[2] G.Venkatkumar1, S.Mohanamurugan2, R.Vijay3 "Multi-response Optimization of Spring Parameters of Two Wheeler Rear Suspension System Using Grey Relational Analysis in Taguchi Method" International Journal of Engineering and Technology (IJET), ISSN: 0975-4024, Vol 6 No 5 Oct-Nov 2014.

[3] S. M. El-Demerdash "ACTIVE SUSPENSION CONTROL WITH AND WITHOUT PREVIEW", PhD thesis University of Leeds, 1995.

[4] Thomas D.Gillespie. "Fundamental of Vehicle Dynamics" Society of Automotive Engineers, Warrendale, USA, pp. 237, 1992.

[5] Czitrom and Veronica " One-Factor-at-a-Time versus Designed Experiments " The American Statistician, Vol. 53, No. 2 , May 1999.

[6] Dragan Sekulić and Vlastimir Dedović. "THE EFFECT OF STIFFNESS AND DAMPING OF THE SUSPENSION SYSTEM ELEMENTS ON THE OPTIMISATION OF THE VIBRATIONAL BEHAVIOUR OF A BUS" University of Belgrade, Faculty of Transport and Traffic Engineering, Vojvode Stepe 305, 11000. Belgrade, Serbia September 2011.

[7] Bor-Tusen Wang. "The effect of system variables on the ride quality of a full tractor and trailer" the fifth international conference of society and vibration,Hsin-Chu, R.O.C, May 1997.

[8] V. R. Naik $\dot{A} *$ and S. H. Sawant $\dot{A}$ "Optimization of Seat Displacement and Settling Time of Quarter Car Model Vehicle Dynamic System Subjected to Speed Bump" International Journal of Current Engineering and Technology, Vol.4, No.4 (Aug 2014).

[9] Jiju Antony "Design of Experiments for Engineers and Scientists" Elsevier Science \& Technology Books, October 2003.

[10] Alisina Shojaeia, H. Metered b, Siamak Shojaeic and S. Olutunde Oyadijid "Theoretical and Experimental Investigation of Magneto-Rheological Damper based Semi-Active Suspension Systems', Shojaei et al. 2013. Int. J. Vehicle Structures \& Systems, 5(3-4), 109-120.

[11] Vladimír Gogaa and Marian Klúcik. "Optimization of vehicle suspension parameters with use of evolutionary computation” Procedia Engineering 48 ( 2012 ) 174 - 179.

[12] Abdullah O. Bafail, Sheikh I. Ishrat, Zahid A. Khan "OPTIMIZATION OF HYDROFORMING PROCESS FOR MANUFACTURING OF STAINLESS STEEL CORRUGATED FLEXIBLE HOSE PIPE USING THE TAGUCHI METHOD”, International Journal of Mechanical and Materials Engineering (IJMME), Vol. 2 (2007). 
APPENDIX-A

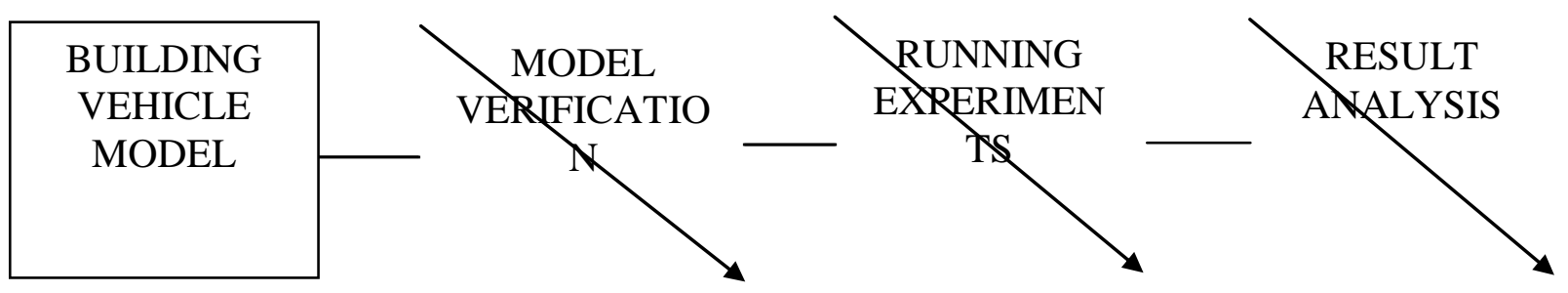

Fig. 1. Schematic drawing of the general steps involved in the DOE Method.

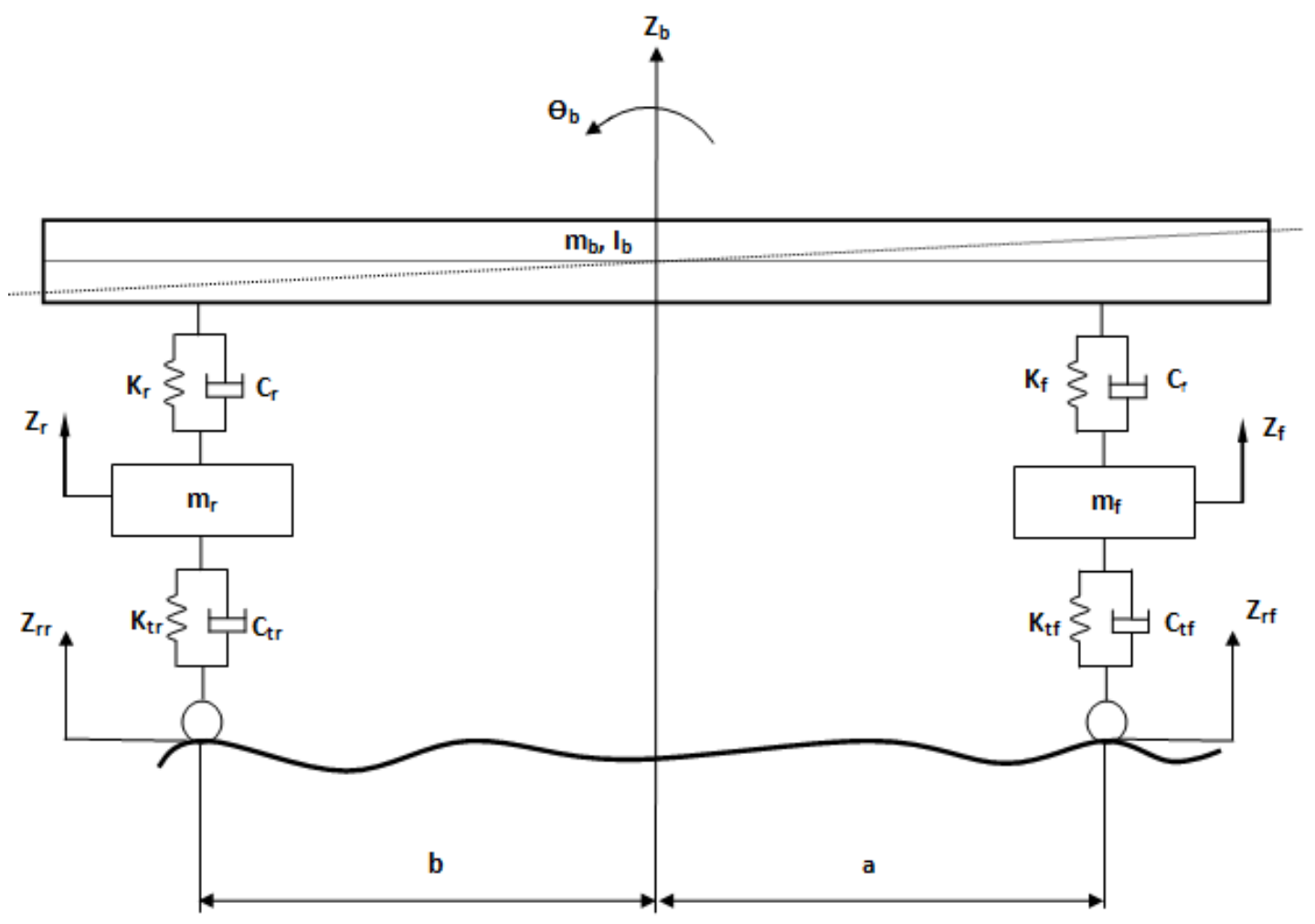

Fig. 2. Passive half vehicle suspension model. 


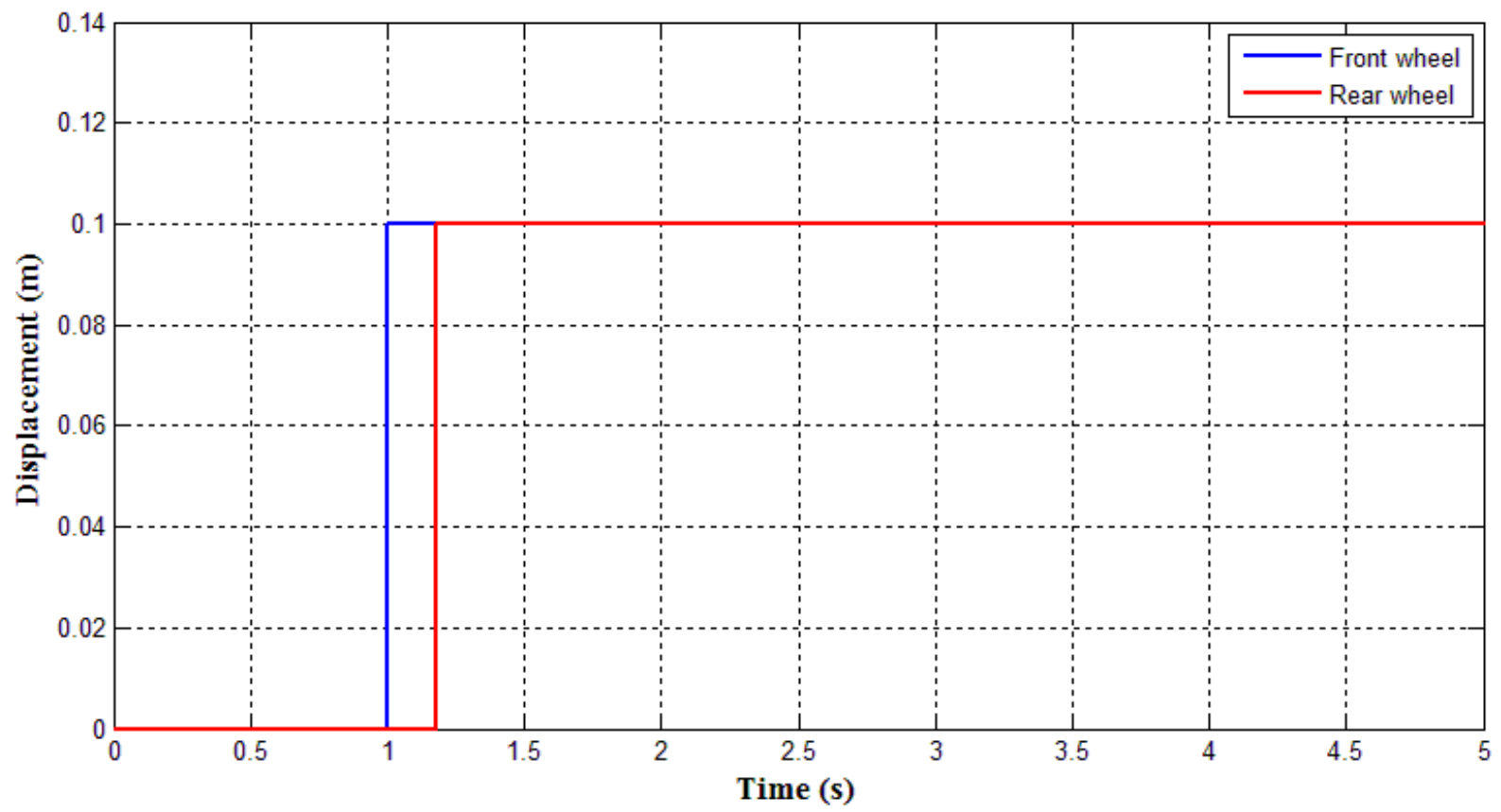

Fig. 3. Road profile.

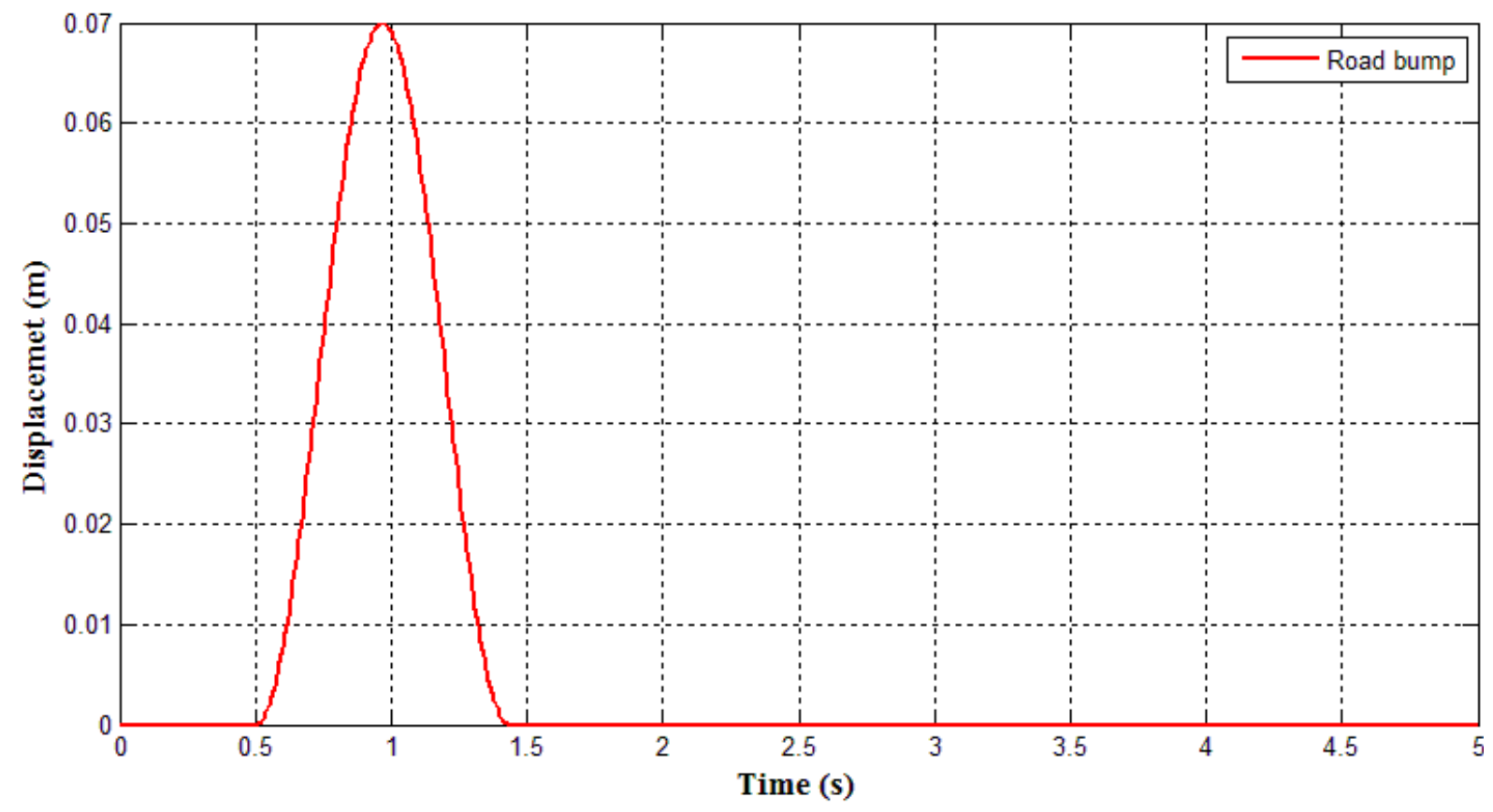

Fig. 4. Road bump profile. 


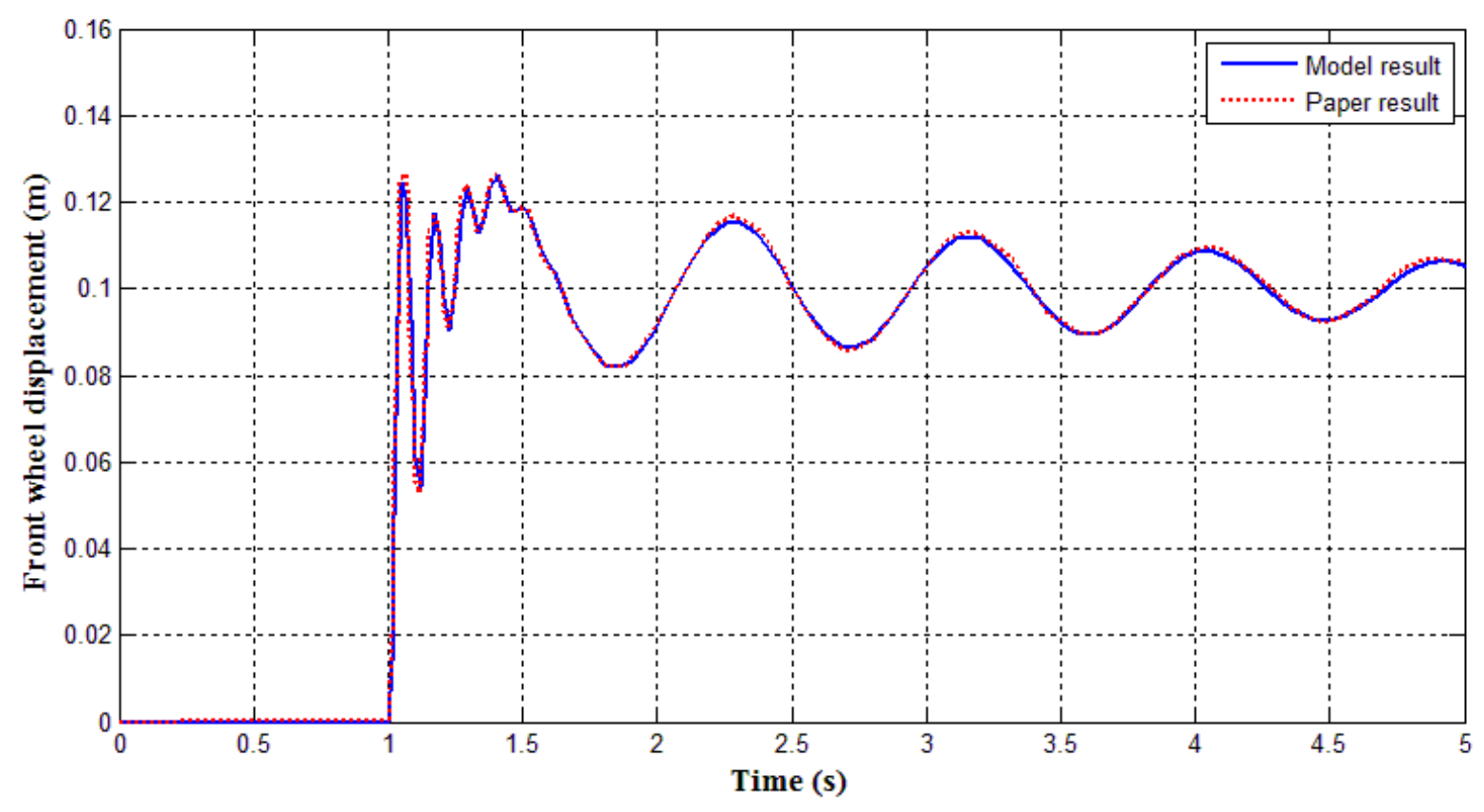

Fig. 5. Rear wheel displacement.

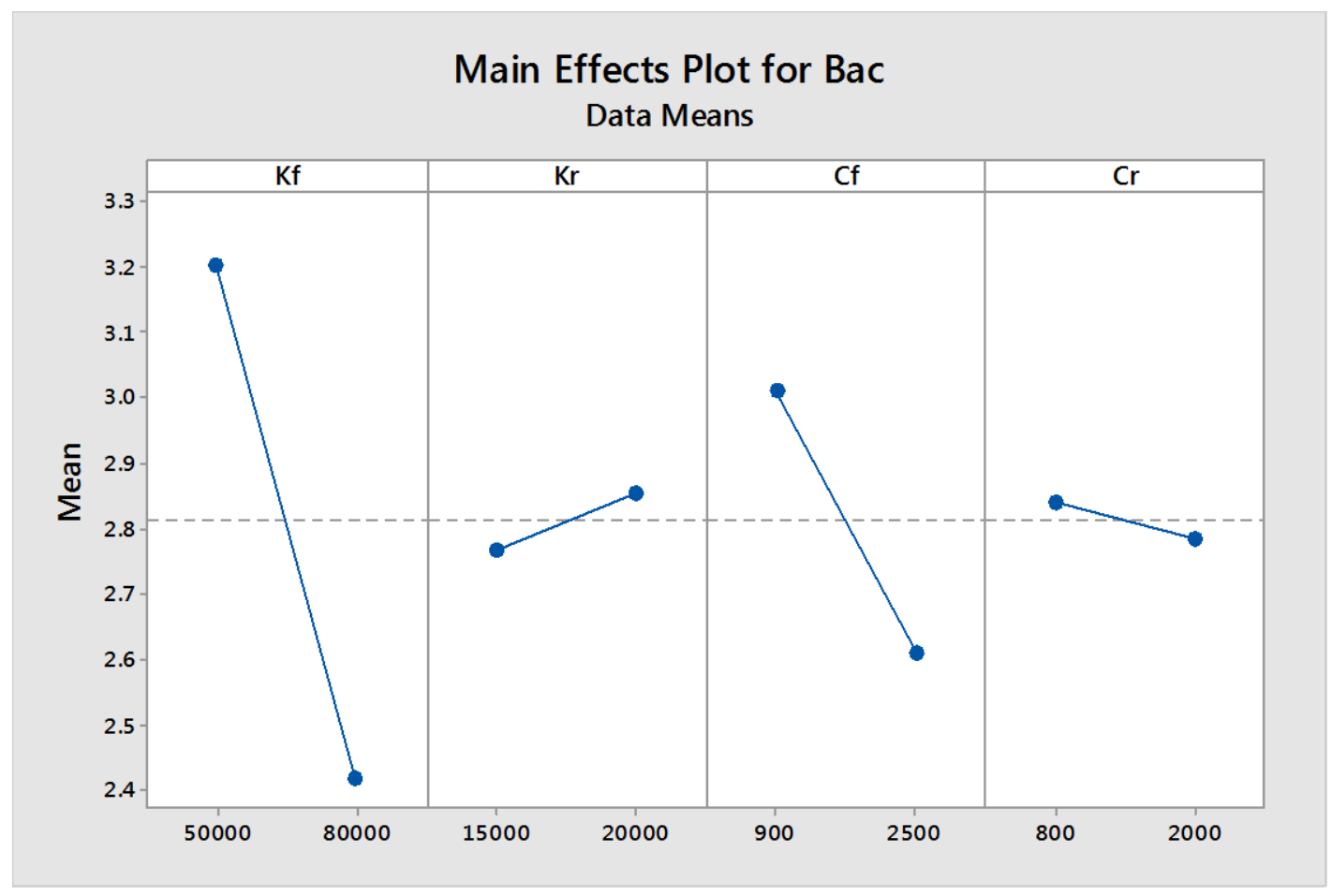

Fig. 6. Main effect plot for vehicle body acceleration. 


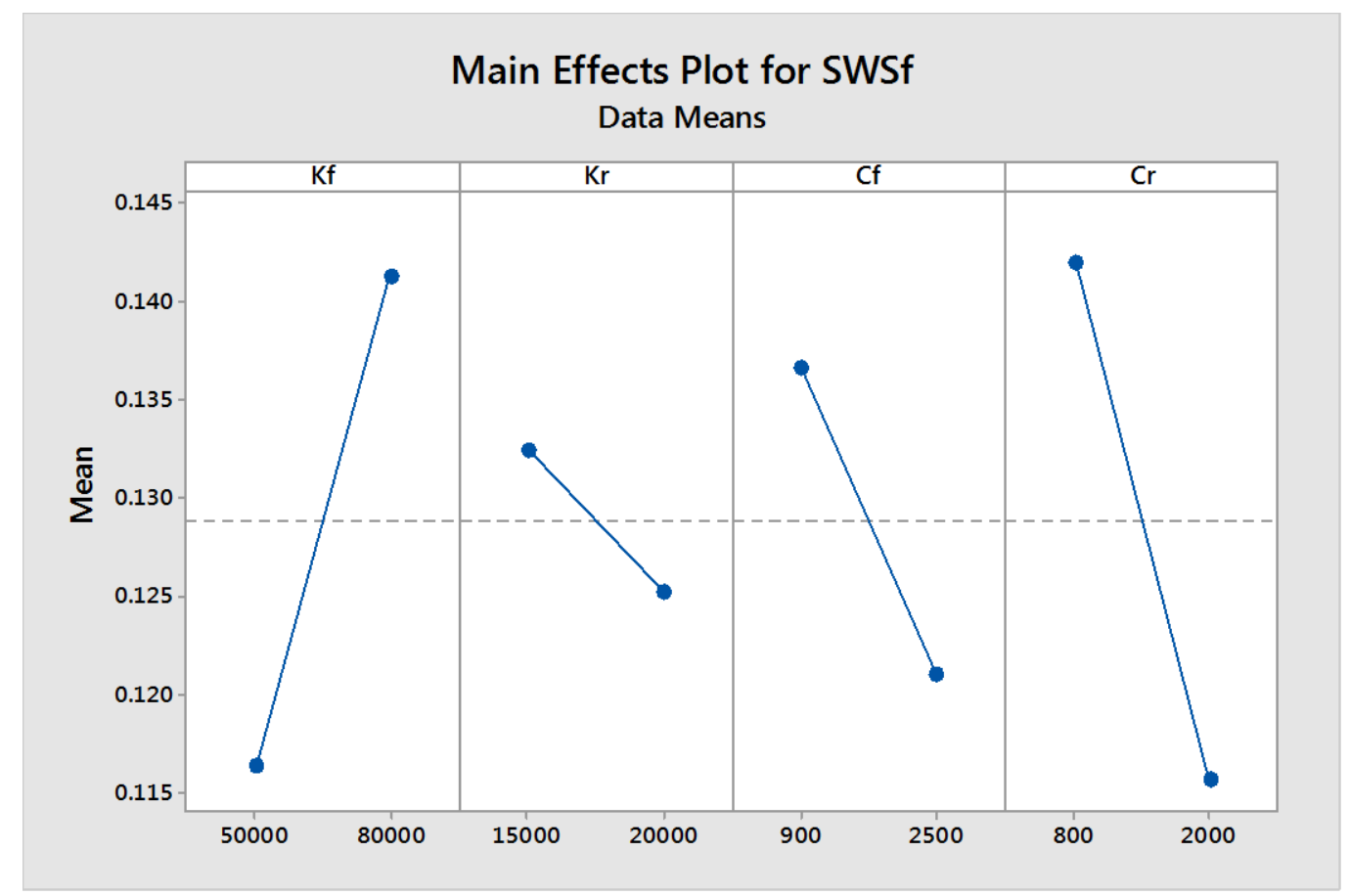

Fig. 7. Main effect plot for vehicle front SWSf.

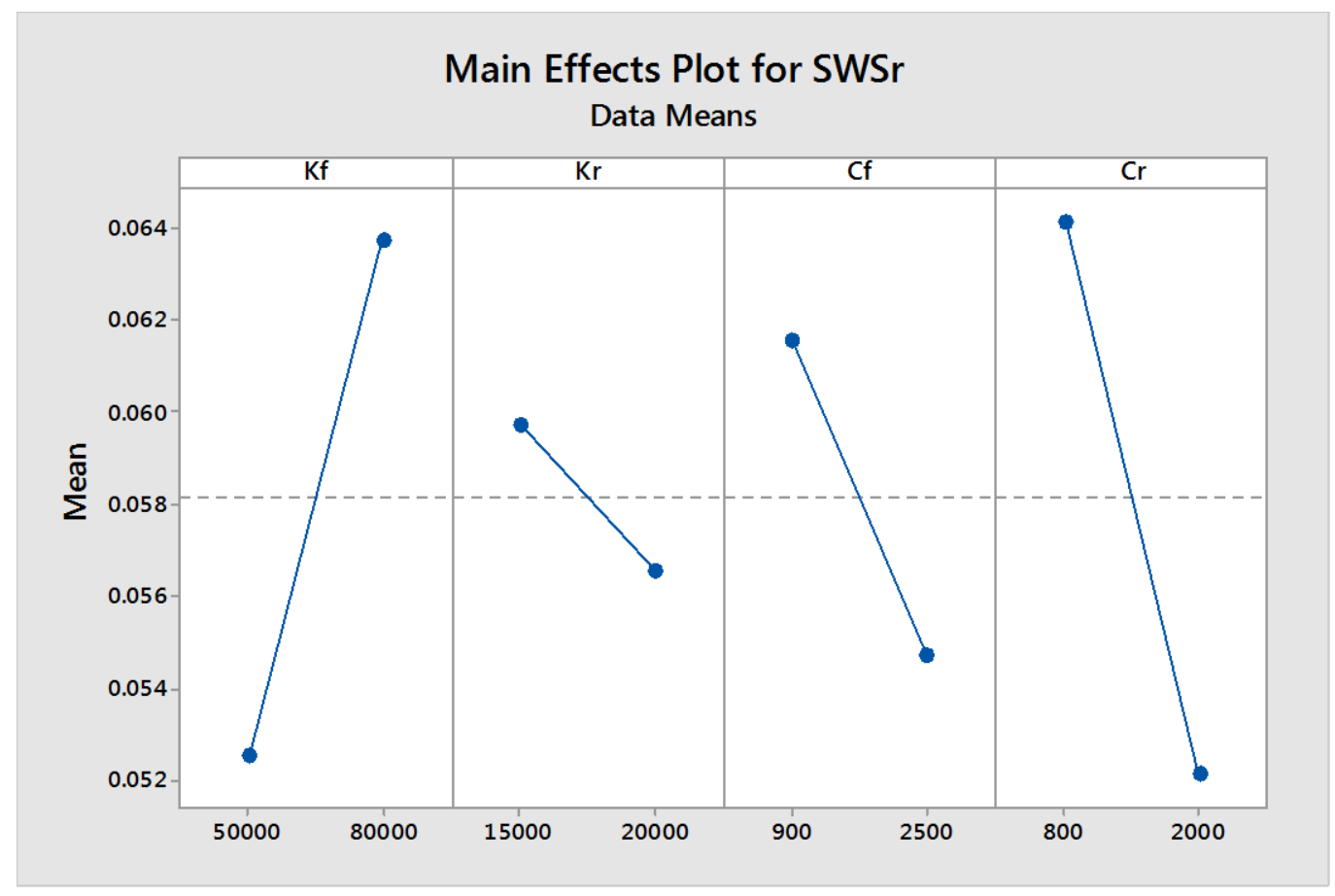

Fig. 8. Main effect plot for vehicle rear SWSr. 


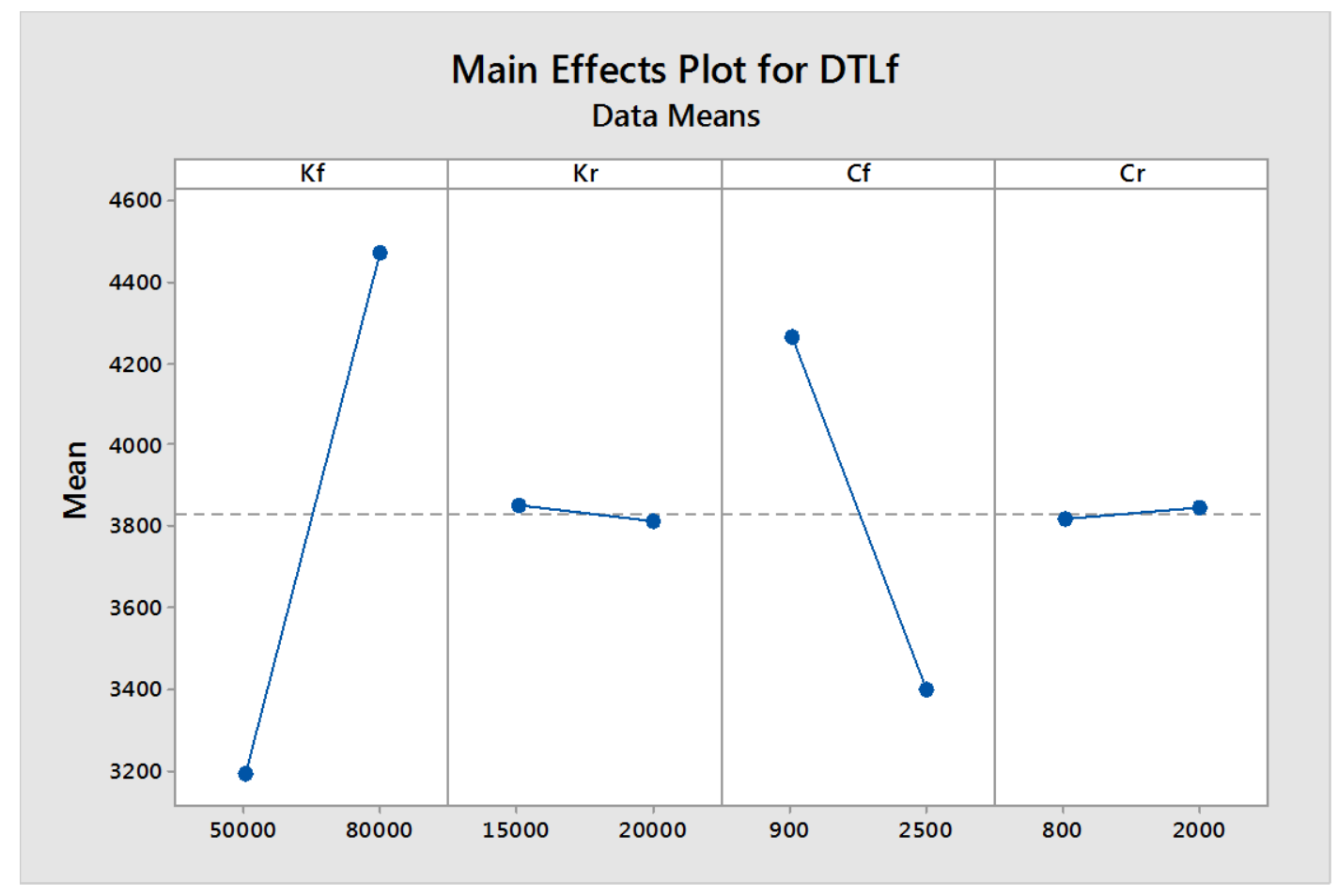

Fig. 9. Main effect plot for vehicle front DTLf.

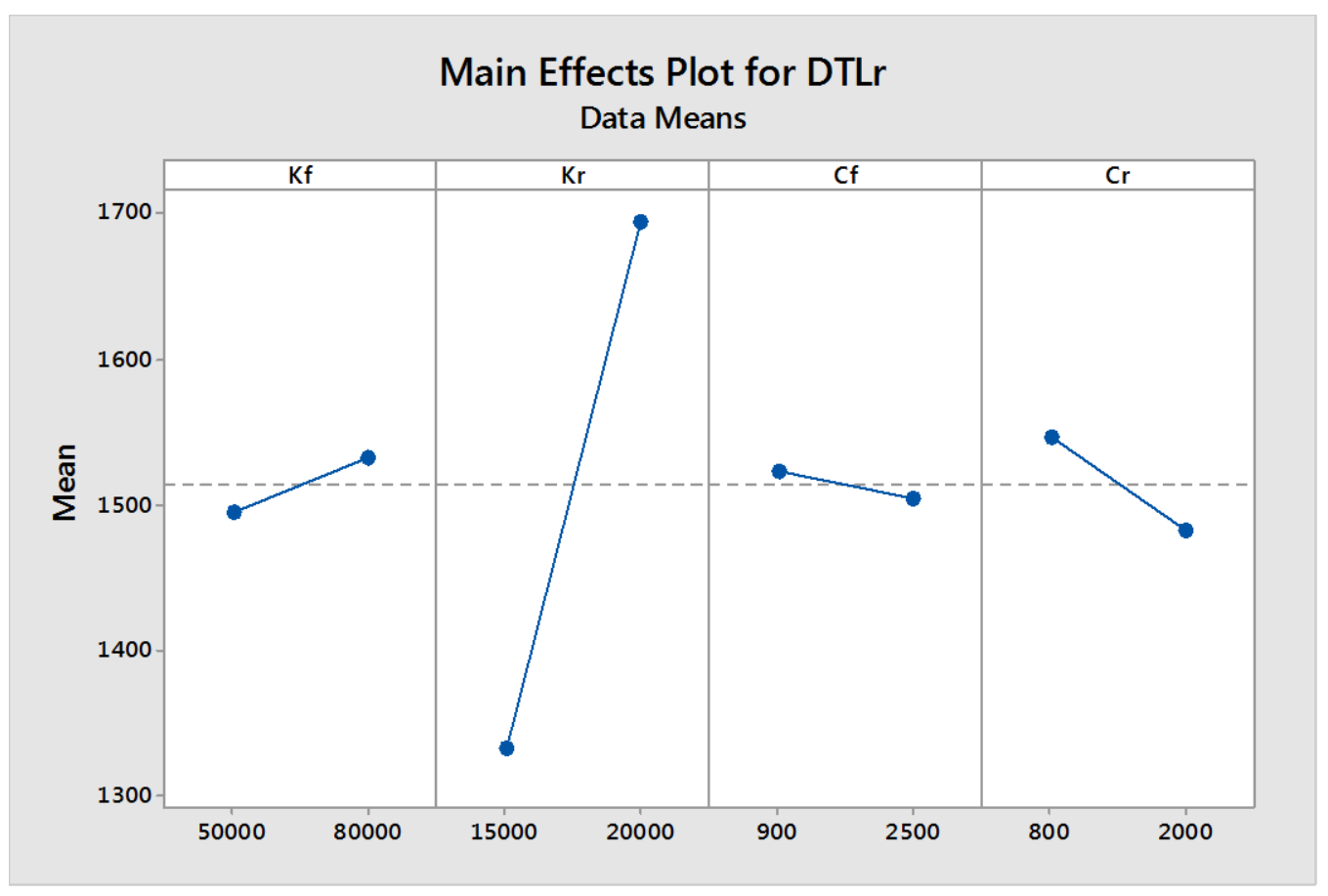

Fig. 10. Main effect plot for vehicle rear DTLr. 


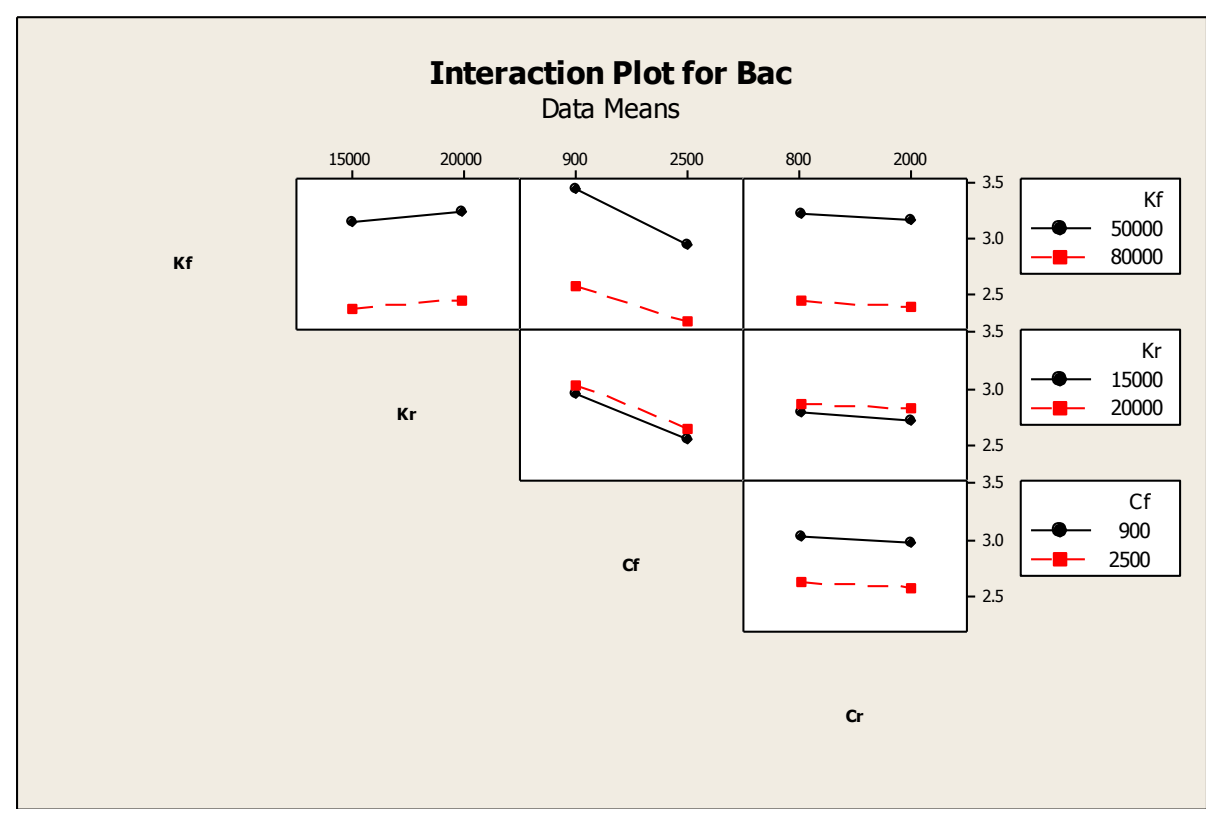

Fig. 11. Interaction effect plot for vehicle body acceleration.

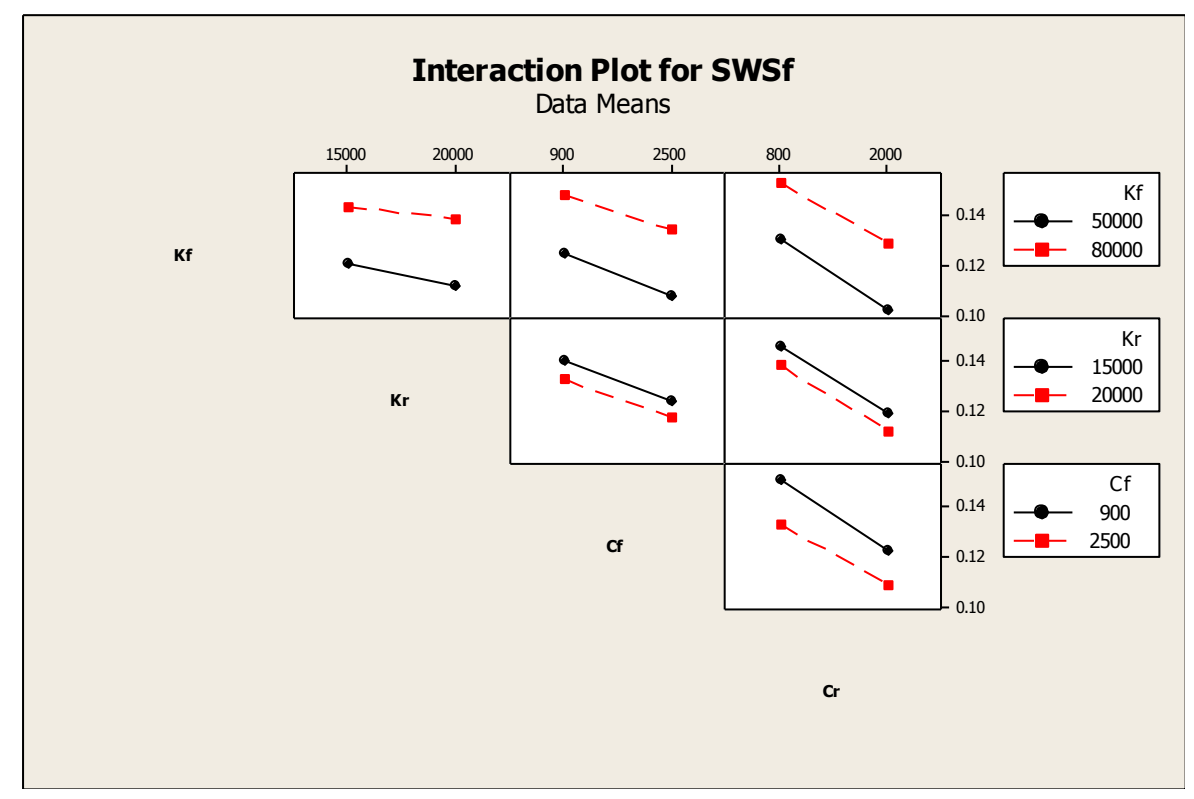

Fig. 12. Interaction effect plot for vehicle front SWSf. 


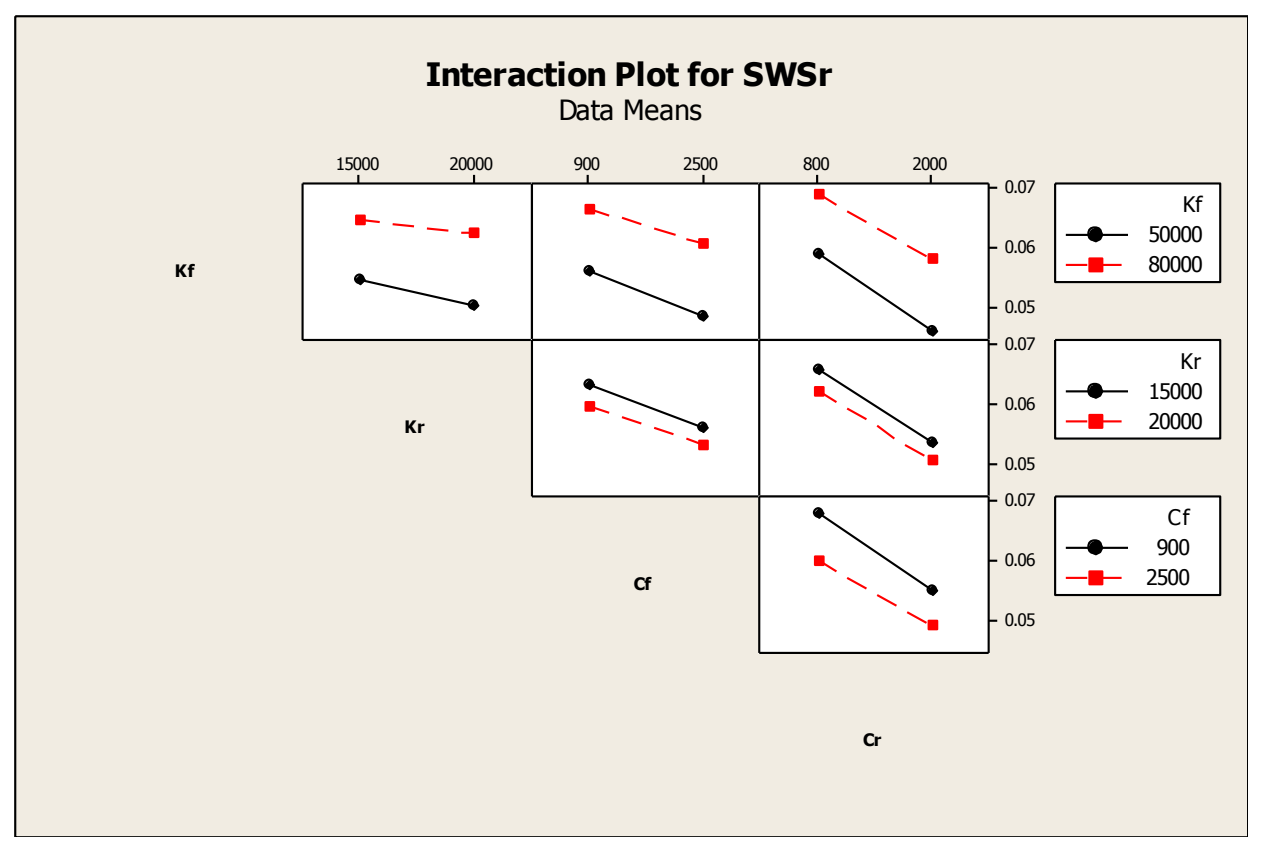

Fig. 13. Interaction effect plot for vehicle rear SWSr.

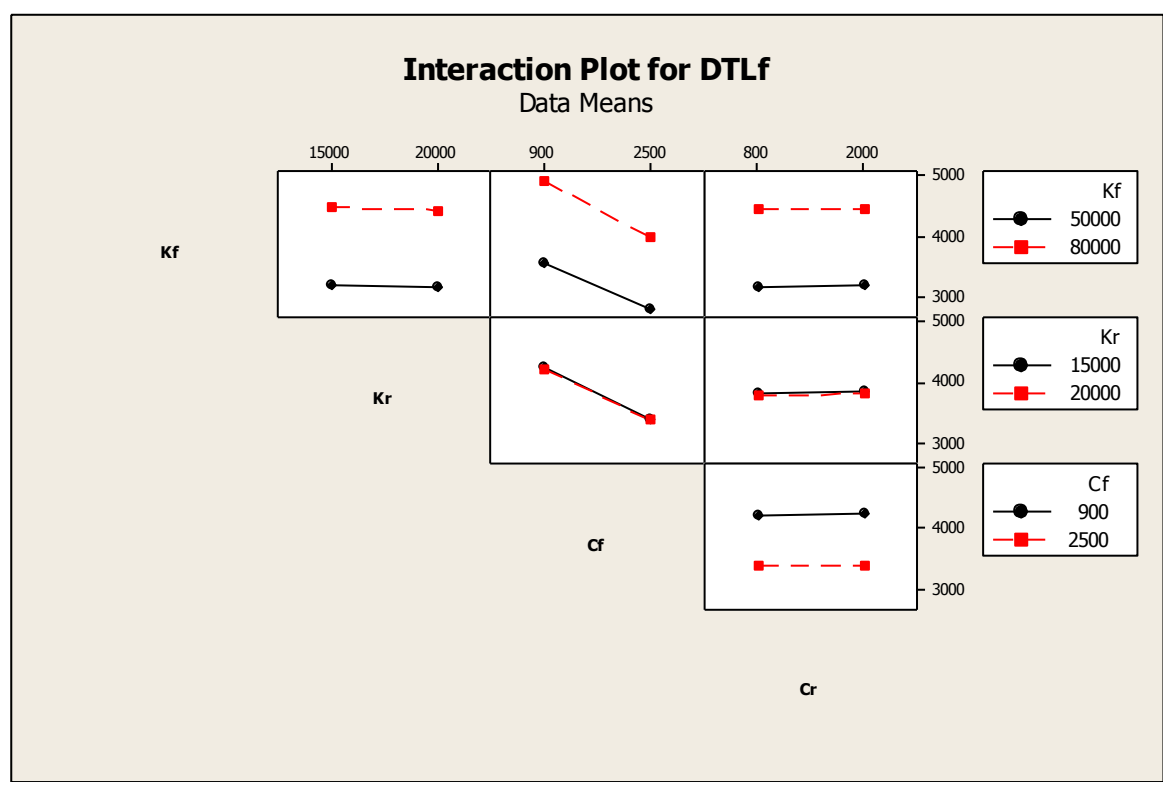

Fig. 14. Interaction effect plot for vehicle front DTLf. 


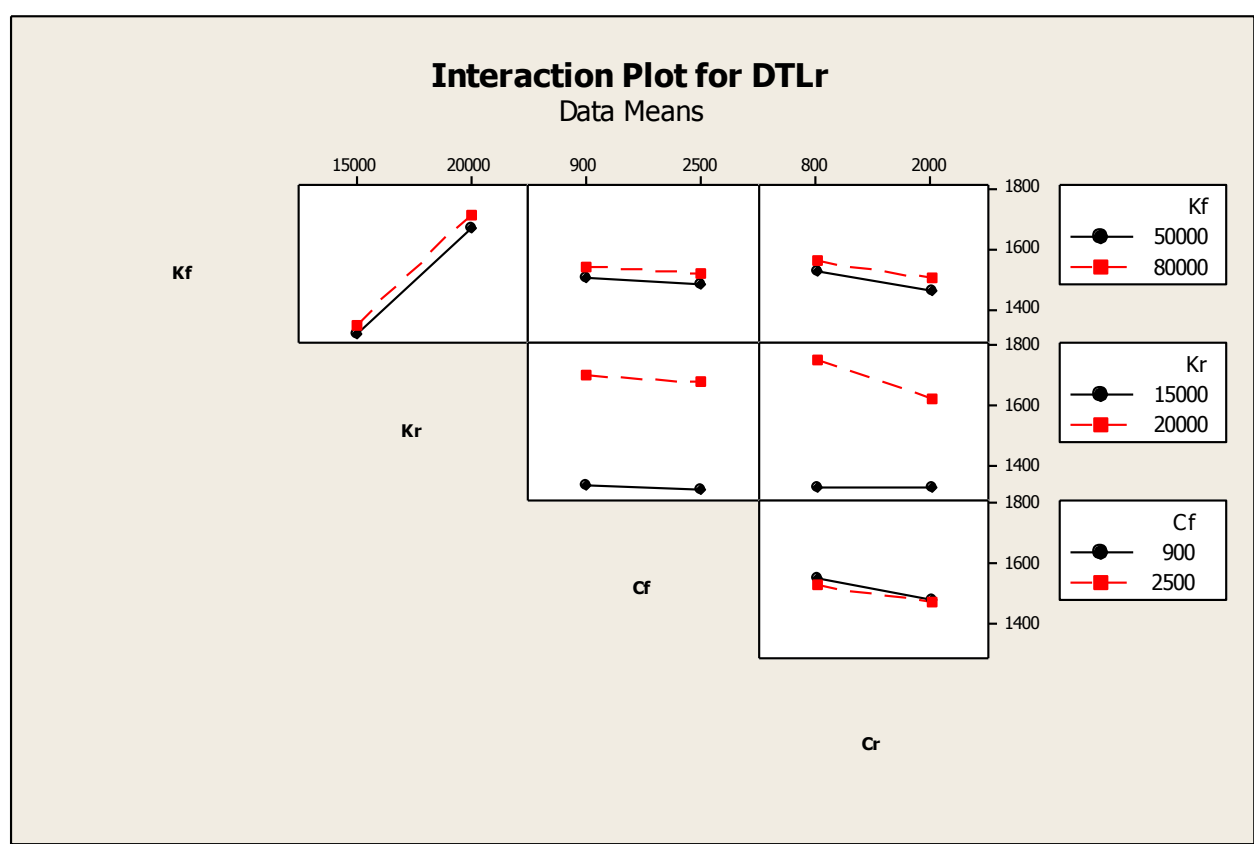

Fig. 15. Interaction effect plot for vehicle rear DTLr.

\section{APPENDIX-B}

Table (1): Parameters of system model [10].

\begin{tabular}{|c|c|c|}
\hline Model Parameters & Value & Units \\
\hline $\mathrm{M}_{\mathrm{b}}$ & 1794 & $(\mathrm{Kg})$ \\
\hline $\mathrm{M}_{\mathrm{f}}$ & 87.15 & $(\mathrm{Kg})$ \\
\hline $\mathrm{M}_{\mathrm{r}}$ & 140.04 & $(\mathrm{~N} / \mathrm{m})$ \\
\hline $\mathrm{K}_{\mathrm{f}}$ & 66824.2 & $(\mathrm{~N} / \mathrm{m})$ \\
\hline $\mathrm{K}_{\mathrm{r}}$ & $18615)$ \\
\hline $\mathrm{C}_{\mathrm{f}}$ & 1190 & $(\mathrm{~N} . \mathrm{s} / \mathrm{m})$ \\
\hline $\mathrm{C}_{\mathrm{r}}$ & 1000 & $(\mathrm{~N} / \mathrm{m})$ \\
\hline $\mathrm{K}_{\mathrm{tf}}, \mathrm{K}_{\mathrm{tr}}$ & 200000 & $(\mathrm{Kg} . \mathrm{m} 2)$ \\
\hline $\mathrm{I}_{\mathrm{b}}$ & 3443.05 & $(\mathrm{~m})$ \\
\hline $\mathrm{a}$ & 1.271 & $(\mathrm{~m})$ \\
\hline $\mathrm{b}$ & 1.713 & \\
\hline
\end{tabular}


Table (2): Maximum absolute values of input parameters and output responses of the model.

\begin{tabular}{|c|c|c|c|c|c|c|c|c|}
\hline $\begin{array}{c}\mathbf{K}_{\mathbf{f}} \\
{[\mathbf{N} / \mathbf{m}]}\end{array}$ & $\begin{array}{c}\mathbf{K}_{\mathbf{r}} \\
{[\mathbf{N} / \mathbf{m}]}\end{array}$ & $\begin{array}{c}\mathbf{C}_{\mathbf{f}} \\
{[\mathbf{N . s} / \mathbf{m}]}\end{array}$ & $\begin{array}{c}\mathbf{C}_{\mathbf{r}} \\
{[\mathbf{N . s} / \mathbf{m}]}\end{array}$ & $\begin{array}{c}\text { Bac } \\
{\left[\mathbf{m} / \mathbf{s}^{\wedge} \mathbf{2}\right]}\end{array}$ & $\begin{array}{c}\mathbf{S W S f} \\
{[\mathbf{m}]}\end{array}$ & $\begin{array}{c}\mathbf{S W S r} \\
{[\mathbf{m}]}\end{array}$ & $\begin{array}{c}\mathbf{D T L f} \\
{[\mathbf{N}]}\end{array}$ & $\begin{array}{c}\mathbf{D T L r} \\
{[\mathbf{N}]}\end{array}$ \\
\hline 50000 & 15000 & 900 & 800 & 3.4183 & 0.1452 & 0.0655 & 3584 & 1323.4 \\
\hline 80000 & 15000 & 900 & 800 & 2.6403 & 0.1638 & 0.0739 & 4959 & 1354.3 \\
\hline 50000 & 20000 & 900 & 800 & 3.5288 & 0.137 & 0.0619 & 3538.2 & 1761 \\
\hline 80000 & 20000 & 900 & 800 & 2.5911 & 0.157 & 0.0709 & 4897.7 & 1797.3 \\
\hline 50000 & 15000 & 2500 & 800 & 2.9352 & 0.1253 & 0.0567 & 2797.1 & 1310.3 \\
\hline 80000 & 15000 & 2500 & 800 & 2.2163 & 0.1486 & 0.0672 & 4023.8 & 1335.5 \\
\hline 50000 & 20000 & 2500 & 800 & 3.0431 & 0.1153 & 0.0522 & 2789.5 & 1726.2 \\
\hline 80000 & 20000 & 2500 & 800 & 2.3362 & 0.1437 & 0.065 & 3967.9 & 1760.5 \\
\hline 50000 & 15000 & 900 & 2000 & 3.3769 & 0.1144 & 0.0514 & 3624.8 & 1318.4 \\
\hline 80000 & 15000 & 900 & 2000 & 2.4637 & 0.1385 & 0.0624 & 4968.7 & 1364.5 \\
\hline 50000 & 20000 & 900 & 2000 & 3.4616 & 0.1033 & 0.0465 & 3599 & 1607.4 \\
\hline 80000 & 20000 & 900 & 2000 & 2.6165 & 0.1335 & 0.0601 & 4928.8 & 1660.4 \\
\hline 50000 & 15000 & 2500 & 2000 & 2.8877 & 0.099 & 0.0447 & 2811.1 & 1313.7 \\
\hline 80000 & 15000 & 2500 & 2000 & 2.2059 & 0.1243 & 0.0561 & 4030.1 & 1349.4 \\
\hline 50000 & 20000 & 2500 & 2000 & 2.9601 & 0.0916 & 0.0414 & 2806.3 & 1601.2 \\
\hline 80000 & 20000 & 2500 & 2000 & 2.2902 & 0.1206 & 0.0545 & 3993.8 & 1643.1 \\
\hline
\end{tabular}

Table (3): Factors with significant main effect on the output responses.

\begin{tabular}{|c|c|c|c|c|}
\hline \multirow{2}{*}{ Response } & \multicolumn{4}{|c|}{ Factors Main Effect } \\
\cline { 2 - 5 } & $\mathbf{K}_{\mathbf{f}}$ & $\mathbf{K}_{\mathbf{r}}$ & $\mathbf{C}_{\mathbf{f}}$ & $\mathbf{C}_{\mathbf{r}}$ \\
\hline BAc & $\checkmark$ & $\checkmark$ & $\checkmark$ & $\checkmark$ \\
\hline SWSf & $\checkmark$ & $\checkmark$ & $\checkmark$ & $\checkmark$ \\
\hline SWSr & $\checkmark$ & $\checkmark$ & $\checkmark$ & X \\
\hline DTLf & $\checkmark$ & $X$ & $\checkmark$ & $\checkmark$ \\
\hline DTLr & $\checkmark$ & $\checkmark$ & X & \\
\hline
\end{tabular}

Table (4): Factors interaction effect on the output responses.

\begin{tabular}{|c|c|c|c|c|c|c|}
\hline \multirow{2}{*}{ Response } & \multicolumn{7}{|c|}{ Factors Interaction Effect } \\
\cline { 2 - 7 } & $\mathbf{K}_{\mathbf{f}} * \mathbf{K}_{\mathbf{r}}$ & $\mathbf{K}_{\mathbf{f}}^{*} \mathbf{C}_{\mathbf{f}}$ & $\mathbf{K}_{\mathbf{f}} * \mathbf{C}_{\mathbf{r}}$ & $\mathbf{K}_{\mathbf{r}} * \mathbf{C}_{\mathbf{f}}$ & $\mathbf{K}_{\mathbf{r}} * \mathbf{C}_{\mathbf{r}}$ & $\mathbf{C}_{\mathbf{f}} * \mathbf{C}_{\mathbf{r}}$ \\
\hline BAc & $\mathrm{X}$ & $\mathrm{X}$ & $\mathrm{X}$ & $\mathrm{X}$ & $\mathrm{X}$ & $\mathrm{X}$ \\
\hline SWSf & $\mathrm{X}$ & $\mathrm{X}$ & $\mathrm{X}$ & $\mathrm{X}$ & $\mathrm{X}$ & $\mathrm{X}$ \\
\hline SWSr & $\mathrm{X}$ & $\mathrm{X}$ & $\mathrm{X}$ & $\mathrm{X}$ & $\mathrm{X}$ & $\mathrm{X}$ \\
\hline DTLf & $\mathrm{X}$ & $\mathrm{X}$ & $\mathrm{X}$ & $\mathrm{X}$ & $\mathrm{X}$ & $\mathrm{X}$ \\
\hline DTLr & $\mathrm{X}$ & $\mathrm{X}$ & $\mathrm{X}$ & $\mathrm{X}$ & $\mathrm{X}$ & $\mathrm{X}$ \\
\hline
\end{tabular}

